\title{
Revitalizing Education through Problem based Learning Practices
}

\section{OPEN ACCESS}

Manuscript ID:

EDU-2020-09013436

Volume: 9

Issue: 1

Month: December

Year: 2020

P-ISSN: 2320-2653

E-ISSN: 2582-1334

Received: 12.09 .2020

Accepted: 28.10 .2020

Published: 01.12.2020

Citation:

Nair, Sindhu Shantha, et al. "Revitalizing Education through Problem based Learning Practices." Shanlax International Journal of Education, vol. 9 , no. 1,2020 , pp. 109-117.

DOI:

https://doi.org/10.34293/ education.v9i1.3436

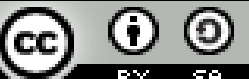

This work is licensed under a Creative Commons Attribution-ShareAlike 4.0 International License

\section{Sindhu Shantha Nair}

Christ (Deemed to be University), Bengaluru, Karnataka, India

D https://orcid.org/0000-0003-1680-716X

\section{S.P. Smritika}

Data Engineer, ICBC, Canada

\section{Kennedy Andrew Thomas}

Director - CEDBEC and

Professor, School of Education, Christ (Deemed to be University), Bengaluru, Karnataka, India

(D) https://orcid.org/0000-0001-7977-222X

\section{Abstract}

Teaching and learning practices need to be revisited to revitalize education. The mundane rote learning due to excessive standardization, pedagogical red tape and routinization often become surfeited and such experiences are discussed by students and teachers alike across the globe. The focus has to shift from content and transmission to problem, process and experience-based learning. This calls for dynamic learning which is challenging since creativity takes over control; reaction takes over responsiveness. Enhanced learning practices take over routine learning providing a rich learning experience for students. Difficult situations or problems prepare and prompt deep thinking and the solutions become learning experiences. Thus problems attract our attention and focus on digging deep into energizing thoughts to solve the same. This rationale and the associated dimensions become the fertile ground for problem based teaching and learning practices. This paper explores the revitalization of education through problem based learning practices. The study highlights the need for a shift from theory base to problem based learning. Redesigning conceptual representations to experience-based, problem based and enquiry based learning can promote relational understanding.

Keywords: Revitalizing education, Problem based learning, Enquiry based learning

\section{Introduction}

Problem based learning emerged in the 1960s in North America, exposing students to real-life problems for deep thinking, and solution-finding working in small groups (Barrows, 1989). It emerged from unhappy experiences in graduate studies among physicians and scientists and the approach and curricula innovations of problem based learning extended very fast to Netherlands, USA, Israel and other states. At least in some areas, the rote learning of subject wise, traditional teacher focussed learning was innovated to student-centered, casebased, context-related learning (Saarinen-Rahiika \& Binkley, 1998; Solomon, Binkley \& Stratford, 1996). Solomon (2005) stated that problem based learning enables learning by students in small groups working through challenging, open-ended problems, facilitated by a teacher, and that the necessary elements in problem based learning are essentially small student groups for learning, the changed role of a teacher from expert to lecture to expert in learning facilitator, the onus of responsibility in their learning shifted to students for self-directed learning, with the learning stimulus being a problem that is written, that which activates prior knowledge to contextual learning and discovery in learning. 
The premises considered for problem based learning was that, contextual learning is unduly over simplified for the integration of complexities involved in problem based learning (Colliver, 2000), Schmidt's (1983) theory of contextual learning along with prior knowledge activation providing better all-inclusive theoretical support for problem based learning (Albanese, 2000), Cooperative learning theory which states that there is the individual dependency on group members for goal achievement which can be extensively used in smaller groups in problem based learning for higher-level problem solving skills (Qin, Johnson \& Johnson, 1995). Curriculum planners initiated the renewed process for problem based learning in early 2000s in McMaster. In McMaster they started with environmental scanning and interviewed residents at McMaster and found that the awareness of problem based learning was already there among the medical residents who used non-problem based learning. Facilitators are the key in the success of problem based learning programmes, through levels of content knowledge about the areas and effective facilitation among groups, with efficiency in the selection of realistic, contemporary and challenging so that residents could investigate cases beyond the medical aspects. The group members or students for this type of learning have to be prepared for supportive activities of the group and willingness for peer teaching and learning. If the clarity of objectives is implemented, and evaluations are unbiased, in amalgamation with student-directed learning, traditional learning can be incorporated with problem based learning. Complex real-life problems may be used as a channel for concepts and principles for student learning, promoting the development of critical thinking, problem solving and communication skills, in turn providing opportunities for group interaction, evaluating methods and findings aiding in life-long learning in contradiction to presenting facts and concepts directly to students in traditional learning (Duch et al., 2001). This type of problem based learning can be injected into any learning case or situation, and can be used in an entire semester and can be adapted with creativity and innovation, with the fact that core problems and concepts may vary among disciplines but, core characteristics or problem based learning must have a frame work that it should motivate students to understand the problem and associated concepts, requires the student to take rational decisions and learn to defend them, incorporate the content objectives and make connection with previous knowledge, initial stages should attract the students to get involved with the problem, through case studies, role-plays and simulations (Duch, et al, 2001). Though this concept came into existence years ago, Problem based learning is still in evolving stages in units, modules, in programmes, across programmes, or shared platforms. Traditionally teachers were not comfortable in the designs and use of problem based learning and sharing platforms. Situations have changed but many are still new to these contemporary concepts vouching for traditional methods. Problem based learning is defined as the "learning that results from the process of working towards the understanding of a resolution of a problem; the problem is encountered first in the learning process (Barrows \& Tamblyn, 1980)". In such learning, focus is shifted from teachers teaching, to student learning, which in turn is a total approach to learning than a technique. The major gap in the industry and academia which employers constantly voice is skill transformation through academics and attitude building. Even today, employers from the industry speak about the industry-academia placement gap, the lacunae in key skills like communication, teamwork, information, creative and critical thinking, problem solving techniques, self- awareness and assessment, reflection, credibility, accountability, ethical behaviour and resilience among prospective students passing out from colleges.

\section{Literature Search}

Schmidt et al., (2009) explained the bottlenecks in problem-based learning as integrating learning, experiencing curriculum relevance to future professions, and enhancing curiosity levels of students in the domain. The challenge is to constantly find new ideas, relevant designs, motivation, creating interest and providing up to date problems for students and assessments. Biggs (2003) stated that student learning is driven through assessments. Thus problem based learning also needs to be assessed in 
alignment to learning outcomes, student capability development, and processes of problem based learning.

Conway and Little (2000) opined that the development of problem-based learning needs to be a major, multi-dimensional, change management project. The associated activities of resources, seminars, lectures and skill-based training and the like needs to be planned, sequenced, and expedited to create and integrate problem-based learning (Kolmos, 2002). This will help the students to enhance their knowledge and capabilities independently through their creativity and concepts which further develops skills for social, emotional, and professional needs (Hmelo-Silver, 2004). To maximize the potential of problem-based learning, and to facilitate the development of wholeness in educative learning, the ways of thinking about the problem and problembased learning has to be changed (Margetson, 1997). Mill (1981) stated that "improvement in mankind is not possible unless a great change occurs in the fundamental constitution of the modes of thoughts."

Integrating teaching, learning and research in higher education is one among the best ways to stimulate deep thinking in students (Barrett \& Moore, 2011). Margetson (1997) proposed several questions for reconsideration of pedagogy; "Do our changes promote educative dialogue in ethical community? Do our changes help overcome the undergraduate/ postgraduate divide? Do our changes help overcome the opposition between vocational and liberal studies? Do our changes promote the integration of scholarship, teaching and research? Do our changes help achieve understanding through praxis?"

A guided program with suitable learning climate was developed by Barrows in 1989. His approach clearly establishes learning environment, ground rules for teacher and student to bring about effectiveness. The seven jump approach (Scmidst \& Moust, 2000) stipulates that "in the problem description, unknown terms and concepts should be clarified; the phenomenon to be explained in defining the problem should be listed; the problem analysis, must be through brain storming to bring about different sets of solutions; the explanations need to be criticises so that it brings about logical interpretations for the phenomenon; self-directed learning issues to be addressed, the gaps of knowledge for self-study to be filled and finding to be shared with the groups for knowledge integration and comprehension of the phenomenon."There is a need to understand the difference between problem based learning tutorials and problem based teaching as stated by Koschmann et al., (2000),

...whereas the goal from tutor's perspective in a conventional tutorial is to bring the tutee to a negotiated level of understanding, the primary objective of the problem based learning tutorial is just to make deficiencies in the learners understanding evident. These deficiencies need not, and usually are not, immediately redressed but instead are deferred as learning issues for later independent study. Further, it can be seen that the problem based learning tutor is attempting to effect a more global change in the tutees' orientation toward learning and knowing (p.63)

Literature explains that quality of a problem, for problem based learning is one that is engaging, motivating, authentic, real-world, open to multiple hypothesis, discussion sustaining, multidimensional (cognitive, social, emotional, ethical), generating or stimulating collaborative enquiry, underlying key concepts for student learning outcomes, development of transferrable skill (graduate attributes of team work, information, critical thinking, problem solving etc.) enhancement (Barrett, 2005; Barrows \& Tamblyn, 1980; Conway \& Little, 2000; Gijselaers, 2005; Jonassen \& Hung, 2008; Margetson, 1997). A problem can be a scenario, story, dilemma, challenge, trigger, or a starting point to learn (Barrett \& Moore, 2011). Barrett and Moore (2011) further explained that concepts for understanding the above problem focus, can involve understanding phenomenon, working on a challenge (design, creativity), finding effective alternative ways to solve the problem, more key concept learning through a trigger, producing product etc. (Fig 1) 


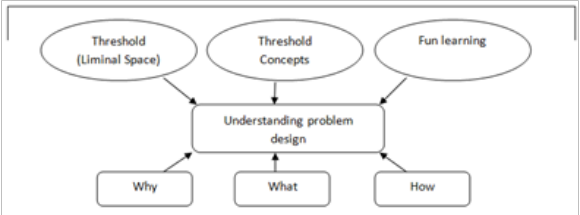

Figure 1: Understanding Problem design, Adapted from new approaches to PBL (Barrett \& Moore, 2011)

Theory of Liminality stipulates that while learning new concepts, knowledge or competencies the direct state of old to new is not possible; first we need to go to the intermediary state which is not completely old or new, but locate in the liminal space to learn (Fig 2). Thus we enter into a transitory space to grow, explore, and work through problems using our creativity. Hence Liminal space can be the threshold, transition phase, stagnation, regression or transformation and PBL can be a provoker of liminal space (Barrett, 2006, 2008).

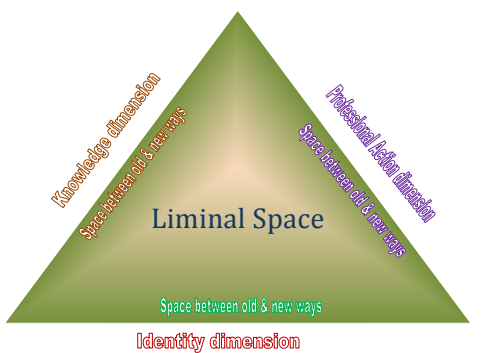

Figure 2: Liminal Space as a Space between Old and New Ways of Learning through PBL (Barrett, 2008)

Mauffette, et al., (2004) stated that, in problem based learning, variety and challenge are crucial. A problem can occur in many ways \& students should be exposed to the diversity of problems to be able to reflect on them. This process should be part of \& whole challenge, to encourage students get into flow of solving why, what, \& how, through fun learning.

People seem to concentrate best when the demands on them are greater than usual and they are able to give more than usual. If there is too little demand on them, people are bored. If there is too much for them to handle, they get anxious. Flow occurs in that delicate zone between boredom and anxiety

(Csikszentmihalyi, 1986, in Goleman, 2006)
The trigger can be through simulated experience or lived experience. The lived experience or phenomenology always brings in reality, along with coping mechanisms and resilience. The strategies used need to be based on concepts and must be reusable (Littlejohn, 2003). The five-step approach by Littlejohn (2003) is given below (Fig 3).



Figure 3: Developing Problems using Five-Step approach to Learning, (Littlejohn, 2003; Cited in Barrette \& Moore, 2011)

This five-step approach encourages the team to brain storming and story boarding. Brainstorming can invoke a lot of ideas. Azer (2007) explained that idea generation through various stakeholders can be richer, contextualized more effectively and arise from different viewpoints. Drummond-Yon and Mohide (2000) and also Hung (2006), stated that, in brainstorming, the learning outcomes have to be identified clearly and also the key concepts of the module or unit of study for the intended problem. The format of the problem and the key decisions to be made is materialized in the Storyboarding level and is a paper-based design to identify all aspects of the problem development and implementation (Barrette \& Moore, 2011). After storyboarding, existing resources can be used. Copyright checking is to protect the intellectual rights of works so that it is not reused without due acknowledgment of the author. The resources then may be delivered for student's usage. If the usage of existing resources does not suffice, then resources can be developed on your own after which the problem can be evaluated for initiating problem based learning (Barrette \& Moore, 2011).

\section{Activating prior Knowledge to Design Problems}

Dolmans et al., (1993) and Jacobs et al., (2003) established the need to design problems to activate 
prior knowledge to facilitate understanding of new knowledge. This is possible through the awareness of student's previous learning from different sources. The prior knowledge can be activated for the development of new knowledge, which is related to the problem interpretation and representation.

\section{The Need for Complexity of Problems}

The complexity feature of the problem will enhance the interpretation and representation, structure, and the content of questions the problem evokes (Abrandt et al., 2001). Simple problems can be easily solved and do not evoke student learning to the desired level since it is not challenging and not linked to real-life (Jacobs et al., 2003). Only when real-life problems are endured, practical solutions are sought after, coping mechanisms are learned and resilience is built. Complex problems, to some extent, may be simulated. For example, in the airline industry lot of simulated learning happen to teach airline operators and pilots the complicated operations involved in the industry. Provocative statements of known knowledge will motivate students to identify, defend, investigate, debate and discuss (Barrette \& Moore, 2011).

\section{Problems and its' Structure}

Three structures may be found in problems, first a rigid structure providing necessary information to solve the problem, second structure that provide facts, to find rest of the facts, and that, which can evoke in-depth learning (BIG learning) for students to investigate beyond the given information, and the third structure is open, or less defined (WIG learning) with non-presentation of data, leaving the students to research the data for more information (Biggs, 2003, cited by Barrett \& Moore, 2011).

\section{Problem Design Guidelines}

If multidisciplinary experts can design problems that trigger through authentic and challenging problem situations, it will activate student's interest to learn. The expertise should be used to link the problem design (Fig 4) to specific outcome learning of knowledge, competence, generic outcomes, teamwork, higher-order thinking skills and information (Barrette \& Moore, 2011). The knowledge acquired and learning ought to be considered for problem designing. The objectives should be aligned to the issues and desired to learn outcomes to motor skills and knowledge. A variety of perspectives from non-subject experts, curriculum developers and librarians can bring in their perceptions.

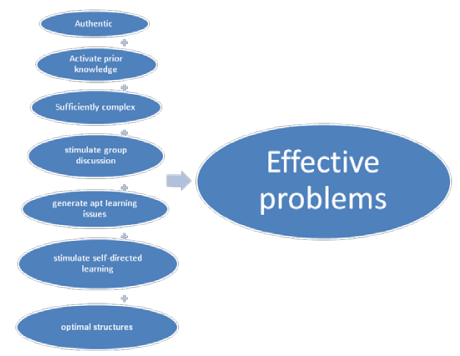

\section{Figure 4: Features of Problems Key to Effective Learning (Barrette \& Moore, 2011)}

The University of Manchester, investigated under the broad term of Enquiry based learning practices for knowledge and skill generation from a research and investigation approach and process. Problembased learning can be a form of inquiry based learning (Barrette and Moore, 2011). Savin-Baden (2003) stated that Problem based learning could take different forms, and Kahn \& O'Rourke (2003) explained that student training to take the challenges of enquiry based learning is highly crucial for the success of this learning mode (Fig. 5)

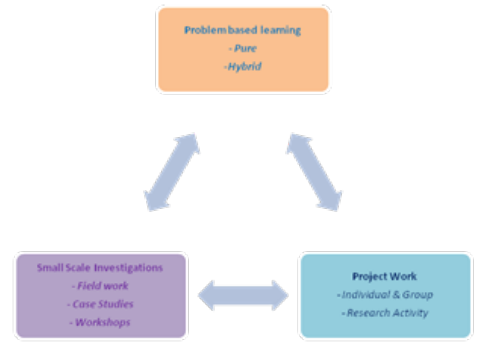

Figure 5: Learning approaches in Equity-Based Learning (Kahn \& O’ Rourke, 2005)

\section{Problem based Learning Environment}

Higher education and student engagement for students are synonymous. The philosophy of my own educational experience will create responsible, empowered, and resilient students to become selfdirected through learning, research, collaboration and teamwork. 


\section{Disadvantages of Problem based learning}

While the above factors point to the advantages of problem based learning, Guido (2016) points out the disadvantages of problem based learning; devoting too much time to problem based learning may cause issues for standardized tests and scoring; secondly, in a class of the mixed group, participation hindrance can happen due to immaturity creating a distraction to other students and undesired outcomes. Unreliability on teachers may cause lack of concept understanding, due to unfamiliarity among some students or students may lack new knowledge or relevant information which is abstract to develop an effective solution, a new teacher with lack of experience in supervising problem based activity may take time to adjust to new teaching-learning habits; assessment of problem based learning seek constant monitoring, note making and segmentation; identification of problems which are relevant, applicable, tangible and creating interest for students can be challenging which may allow students to divert from the objectives and learning outcomes may be missed. Students may run into unanticipated problems and obstacles in the case compromising the teacher's planning and making it hard to be on track.

\section{Future of Problem based Learning}

Though few disadvantages exist, these can be mitigated by active monitoring, helpful resources, guiding questions, articles to read, teaching style, finding a tangible problem relevant to students to allow them to contextualize and apply to future challenges will definitely improve knowledge, skills, self-directed learning and make them empowered. Problems from School, College, and Community, student's shared interests, wherein the problem and the information is well understood by the students will add value. The objective and outcome needs to be perfectly matched and the purpose of the problem and the accomplishment by running the challenge need to be clearly defined. For example, team work, collaborative skill, problem-solving capability and processing diverse content can be the purpose of a problem based learning. Teachers may provide helpful material sources, data to help the context of the problem, video, audio, or presentations, list of questions to investigate thereby setting goals and expectations, participating by filling gaps of knowledge, providing hints (not answers), questioning student conclusion or logic, providing insights and encouraging them to analyse, dividing into small teams for thoughts/idea generation and present in front of the class, encouraging the student audience to pose questions so that the presenting group can elaborate and debate with evidence will bring in effective problem based learning.

\section{Discussion}

Problem-based learning was initiated in the medical syllabus and was extended to other sectors, with simulated environments. Slowly and steadily, it was introduced to some segments of students for different educational levels. The benefits of problem based learning, typically for students, are; greater understanding, higher abilities, lifelong learning skills, and is more enjoyable and satisfying with a student-centered approach. While the benefits of problem based learning for teachers are interdisciplinary promotion, more study time with students, increase in class attendance due to fun learning and intrinsic rewards for teachers. As far as institutions are considered, the multi-benefits are better-engaged teachers, better-engaged students, prioritized student learning, student retention, teacher retention, low attrition, an institutional value in teaching, learning and knowledge dissemination. A few imperils of problem-based learning for students are the possibilities of less content knowledge being imparted, team dynamics if not proper, may pose a bigger issue, since learning is practical and complex, a certain degree of anxiety may occur among students; prior learning experience may not prepare students for problem based learning and may require more time, which in turn leave less time for other content learning. For teachers, a few risks may be, creating or simulating exciting, creative and complex problem scenarios or simulations is often timeconsuming and difficult; tedious preparation time for problem based learning, including the answers for possible queries from students; interventions for team dynamics and issues; what to assess and how to assess. For institutions, a few perils may be, a change of scenario in the philosophy of education from conventional lecture to problem-based learning 
structure, staff development, training and support, requirement for more teachers for simulated learning, space, infrastructure and flexible learning, resistance for change from existing teachers from conventional teaching methods and questioning efficacy of problem-based learning with less importance for content learning. Teachers often miss reflecting on the thought, how much the students are absorbing from the lecture, or is there a better way to teach them, is the rote learning helping them to think for themselves, or able to develop skills for later life and existence? Often the lecture leaves with information overload and deep learning happens only with problem based learning, developing skills for life and solving life problems. Also, problem based learning enables students for parameter setting, investigating within these parameters, and engaging them, wherein the traditional teacher becomes a coach or guide. It fosters analytical thinking, collaboration, problem solving, clarity in thinking and connect problems to practicalities in real life and find solutions. Hildebrand, Mulcahy, and Wilks (2011), stated that problem based learning enables students to be openminded, reflective, and critical for active learning, to make learning meaningful, to strategize learning for future, irrespective of the subjects. While traditional teaching prepares students to remember definitions, theory and contents, higher-order thinking skills in problem-based learning develop their thinking skills, evaluate, hypothesize, synthesize, analyze and generalize. From a young age, group involvement enables them to learn team dynamics, which will go a long way in personal and professional life working in teams in an office environment. The fundamental skill in team dynamics of effective communication, active listening, negotiation, and cooperation are learning for life and enable easy application to other environments. The assessment learning in problembased learning, will equip the students for selfdirected learning, analysis and evaluation, which are essential in exponential technology. It is beyond the school examinations which is basically a memory test.

The greatest challenge in problem-based learning is to design problems for learning and engaging students. An ideal scenario is a real problem for which students will be able to connect prior experiences with a proper frame work and structure connecting content and problem-solving skills, relatively open-ended for the flexibility of ideas and findings for effective solutions. It should have the depth to enable students to ask questions of what, why and how, challenging the liminal space for identity dimension. The onus on students is self-directed learning since they design the learning structure to find effective solutions. Thus the problem has to be real for them to carry out this self-directed learning. For team dynamics to be effective, an ideal team climate must be created with groups of a minimum of three members to a maximum of five members. To begin with, fewer members or minimum members enable the team to voice opinions, communicate well, actively listen, negotiate, reach a consensus and contribute.

The problems for learning need to be stimulating, to work for a response or solution, and the environment for learning has to be created for effective learning. With a teacher as facilitator and an effective environment, model questioning and support will highly engage the students. The teacherfacilitator approach will help scaffold thinking skills, to develop and direct their thinking to what they know, what they need to know and what they do not know, rather than the conventional provision of providing knowledge for solving problems. Teacherfacilitators' may guide to probe into the known and unknown space, as leads, into model thinking, demonstrating behavior to hypothesize, analyze, synthesize, generalize and to encourage them to reflect on the content and methods used, which will help build student confidence, for them to become self-motivated, self-directed, independent learners. The model for teachers, developed by Hildebrand, Mulcahy and Wilks (2001), for problem-based learning, explains three phases, the first phase being the problem encounter phase, second, the doing phase and third being the drawing together phase. The first phase of the problem encounter helps in building concept maps and mind maps of how to go about the problem, which leads to a lot of questions about what is known and what needs to be known. The second phase enables them to research the problem and collect evidence and information they need to solve the problem and the third phase allows them to communicate, listen, negotiate possible solutions 
and outcomes, to decide on a consensus and solve the problem. Once the students are experienced with various possibilities of solving problems, they equip themselves with confidence, take decisions independently and become self-directed and resilient, the most wanted qualities practically for the professional and personal environment.

\section{Conclusion}

The problem-based learning effectiveness can differ from teams, groups, class rooms, and individual students. Researches on problem based learning show that listing questions can let students be on track. But in the future the extent of this can be mapped with the challenges of the problem. As Nilson (2011) stated, the learning outcomes from problem based learning are many; oral and written communication, team building, leadership roles, managing projects, self-awareness, group evaluation, independent working, critical thinking, analytical skills, concept understanding, self-direction and learning, applying prior knowledge and course content to problem solving for real-world problems, researching abilities, information literacy, solving problems across disciplines. While the traditional lecture method teaches relevant information, teaching the students to apply the lectured knowledge, to solve problems, in problem based learning, students are presented with the problem first and allowed to engage in solving the problem, through examination of the problem, engaging in a group discussion to define the problem, determine the learning, information acquisition, necessary tools, evaluate possible ways, solve the problem and report the findings. Student engagements are being recognized at all levels in higher education and are seen as active participants or their directors of the educational experience. Student engagement culture in higher education calls for strategies and involving students as partners of the learning community. Enabling student-centred learning, empowering students to be actively involved in disciplines and departments to develop will provide efficient, effective methods of student involvement to devise, implement and evaluate problems, improve in learning and will lead to peer mentoring also. Symposiums, open discussion forums, student engagement activities, academic and social integration to create a climate for cohesive programs to call for student support as partners for strategic goals will recognize the need for proactive partnership from students, will engage students in the development and delivery of problembased learning through inquiry.

\section{References}

Autobiography and Literary Essays, Collected works of John Stuart Mill, edited by John M. Robson and Jack Stillinger, University of Toronto Press, 1981.

Azer, Samy A. "Twelve Tips for Creating Trigger Images for Problem-Based Learning Cases." Medical Teacher, vol. 29, 2007, pp. 93-97.

Barrett, Terry. "A Problem as a Provoker of a Space Betwixt and between Old and New Ways of Knowing." Understanding Problem Based Learning, edited by Esa Poikela and Anna Raija Nummenmaa, Tampere University Press, 2006, pp. 33-50.

Barrett, Terry. "Philosophical Principles for ProblemBased Learning: Freire's Concepts of Personal Development and Social Empowerment." The Power of Problem based Learning, 2011.

Barrett, Terry. "Researching the Dialogue of Problem-based Tutorials: A Critical Discourse Analysis Approach." Challenging Research into Problem based Learning, edited by Savin-Baden, M., and Kay Wilke, Open University Press, 2004, pp. 93-102.

Barrett, Terry. "The Problem based Learning Process as Finding and being in Flow." Innovations in Education and Teaching International, vol. 47, no. 2, 2010, pp. 165-174.

Barrows, Howard S. The Tutorial Process, Southern Illinois University School of Medicine, 1989.

Biggs, John, and Catherine Tang. Teaching for Quality Learning at University, Society for Research into Higher Education \& Open University Press, 2003.

Cotton, Caroline. "Real-world and Active - the Benefits of problem-based Learning." Teacher Magazine, 2014.

Drummond-Young, M., and E.A. Mohide. Developing Problems for Use in Problem based Learning, 2000. 
Duch, Barbara J., et al. The Power of Problem-Based Learning, Stylus Publishing, 2001.

Grasha, Anthony F. Teaching with Style: A Practical Guide to Enhancing Learning by Understanding Teaching and Learning Styles, Alliance Publishers, 1996.

Hildebrand, G., et al. "Learning to Teach through PBL: Process and Progress." Teacher Education, Change of Heart, Mind and Action, 2001.

Hmelo-Silver, Cindy E., and Howard S. Barrows. "Goal and Strategies of a Problem based Learning Facilitator." Interdisciplinary Journal of Problem-Based Learning, vol. 1, no. 1, 2006.

Hmelo-Silver, Cindy E. "Problem Based Learning; What and How do Students Learn?" Education Psychology Review, vol. 16, 2004, pp. 235-266.

Hung, Woei. "The 3C3R model: A Conceptual Framework for Designing Problems in PBL." The Interdisciplinary Journal of Problem Based Learning, vol. 1, no. 1, 2006.

Koschmann, Timothy, et al. "When is a Problembased Tutorial not a Tutorial?" Problembased Learning a Research Perspective on Learning Interactions, Lawrence Erlbaum Associates, 2000.

Littlejohn, Allison. Reusing Online Resources: A Sustainable Approach to E-learning, Kogan Page, 2003.

Lohfeld, Lynne, et al. "PBL in Undergraduate Medical Education: A Qualitative Study of the Views of Canadian Residents." Advances in Health Sciences Education, vol. 10, 2005, pp. 189-214.

Margetson, D. "Wholeness and Educative Learning: the Question of Problems in Changing to Problem based Learning." International Conference on Problem-Based Learning, Brunel University, 1997.

Mauffette, Yves, et al. "The Problem in Problembased Learning is the Problems: But do they Motivate Students?" Challenging Research into problem based Learning, edited by Maggi Savin-Baden and Kay Wilkie, Society for Research into Higher Education, 2004, pp, 11-25.

Neufeld, V.R., and H.S. Barrows. "The "McMaster Philosophy": An Approach to Medical Education." Journal of Medical Education, vol. 49, 1974, pp. 1040-1050.

Nilson, Linda B. Teaching at its Best: A Researchbased Resource for College Instructors, Jossey-Bass, 2010.

Pawson, Eric, et al. "Problem-based Learning in Geography: Towards a Critical Assessment of its Purposes, Benefits and Risks." Journal of Geography in Higher Education, vol. 30, no. 1, 2006, pp. 103-116.

Scmidst, H.G. "Problem based Learning; Rationale and Description." Medical Education, vol. 17, no. 1, 1983, pp. 11-16.

Solomon, Patricia. "Problem-based Learning: A Review of Current Issues relevant to Physiotherapy Education." Physiotherapy Theory and Practice, vol. 21, no. 1, 2005, pp. 37-49.

\section{Author Details}

Sindhu Shantha Nair, Christ (Deemed to be University), Bengaluru, Karnataka, India,

Email ID: sindhusonnet@gmail.com

S.P.Smritika, Data Engineer, ICBC, Canada, Email ID: smritika246@gmail.com

Kennedy Andrew Thomas, Director - CEDBEC and Professor, School of Education, Christ (Deemed to be University),Bengaluru, Karnataka, India, Email ID: kennedy.andrew@christuniversity.in 